\title{
Cien años con Alejo Carpentier ${ }^{1}$
}

\author{
Carlos García-Beidoya M. \\ Universidad Nacional Mayor de San Marcos
}

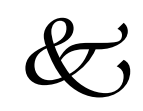

\begin{abstract}
Resumen
El presente artículo destaca el rol del escritor abano Alejo Carpentier en la configuración de la denominada nueva narrativa hispanoamericana. Se examina el impacto del vanguardismo sobre esa vertiente narrativa. Se aborda la etapa inicial de la dora literaria canpenteriana en el contexto de las vanguardias históricas latinoamericanas de los años 20-30. La asimilación del aporte de la vanguardia se combina con una atención del aporte africano a la cultura caribeña. Se evalúa luego el impacto en su producción de las teorías del real ismo mágico o de lo real maravilloso y sus conexiones con el surrealismo. Finalmente se examina el aporte de los modelos de la novela histórica de la narrativa de Canpentier.
\end{abstract}

Palabras claves: Carpentier, nueva narrativa hispanoamericana, vanguardismo, real maravilloso.

Halar de Alejo Canpentier es hablar de una de las figuras centrales H en el proceso de renovación de la narrativa hispanoamericana, proceso que alcanzará su momento estelar con el celebrado "boonl" de los años $60^{2}$. Ese término tomado del marketing, "boom", ha sido utilizado para designar un momento excepcional para la literatura de Hispanoamérica, en especial la novela. Esos años, los llamados "años maravillosos" de los 60, vieron la confluencia, bastante inusual, de alta calidad literaria y éxito comercial masivo. La vasta difusión internacional de esa producción narrativa colocó en el centro de la escena literaria mundial a figuras como Julio cortázar, Carlos Fuentes, Mario Vargas Ilosa y, sobre todo, a Gabriel García Márquez, curya novela 
Cien años de soledad, de 1967, es la expresión más espectacular de ese resonante "boom". Pero también puso en el candelero la obra de algunos autores de más edad, que habían publicado obras importantes en las décadas anteriores y que seguían produciendo en los 60, pero cuyo reconocimiento intemacional había sido hasta entonces escaso.

Entre estas figuras destacaban, en especial, el guatemalteco Miguel Ángel Asturias, el argentino Jorge Luis Borges y el cubano Alejo Carpentier. Generosamente, algunas de las estrellas del "boom" tuvieron a bien reconocerlos como sus antecesores. En verdad, eran mucho más que eso, pues el "boom" no fue sino el momento culminante de un proceso largo y arduo de afirmación de la nueva narrativa hispanoamericana. Cuando retumba el "boom" de los 60, cuenta con el respaldo de una producción de alta jerarquía estética en el cuento y la novela, acumulada en especial en las dos décadas anteriores. Para confirmar la solidez de esa nueva narrativa que remata en el éxito de público del "boom", bastará mencionar unas pocas obras: El Señor Presidente (1946) y Hombres de maíz (1949), de Miguel Angel Asturias; Ficciones (1944) y El Aleph (1949), de Jorge Luis Borges; El reino de este mundo (1949) y Los pasos perdidos (1953), de Alejo Canpentier; La vida breve (1950), de Juan Carlos Onetti; Los ríos profundos (1958) , de Jasé María Arguedas; El túnel, de Emesto Sábato (1948); El Ilano en Ilamas (1953) y Pedro Páramo (1955), de Juan Rulfo.

Si quisiéramos destacar un año crucial en el proceso de maduración de esa nueva narrativa, podríamos escoger el año de 1949. En ese año, tres figuras descollantes, tres fundadores auténticos de la nueva narrativa, Asturias, Borges y Carpentier, a quienes cabe llamar el ABC de la nueva narrativa hispanoamericana, publican obras esenciales, Hombres de maíz, El Aleph y El reino de este mundo, respectivamente. Desde este año clave, podemos hablar ya no de algunas obras aisladas, sino de una nueva narrativa consolidada y pujante.

Pero aquí resulta pertinente preguntarse ¿en qué reside la novedad de esta nueva narrativa? Pues, es obvio que esta denominación "nueva narrativa hispanoamericana" resulta bastante vaga e imprecisa. Nueva, en tanto se aparta de las orientaciones que predominaban en la novela y el cuento de Hispanoamérica en los años 20 y 30, o sea, las orientaciones regionalistas (mundonovistas) de corte realista, 
representadas por obras como Doña Bárbara del venezolano Rómulo Gallegos, Don Segundo Sombra del argentino Ricardo Güiraldes y La vorágine del colombiano José Eustasio Rivera, las denominadas por Marinello "tres novelas ejemplares de América" . La ruptura con esa tradición ocurre esencialmente porque sus discursos narrativos se organizan a partir de innovadores códigos literarios, los procedentes del vanguardismo ${ }^{3}$.

Cuando hablamos del vanguardismo, nos remitimos inmediatamente a los diversos "ismos", las diversas tendencias de la vanguardia europea anterior o inmediatamente posterior a la Primera Guerra Mundial (futurismo, expresionismo, dadaísmo, surrealismo, etc.) , tendencias aryas expresiones más notorias se suele vincular con la poesía. Pero al lado de esa poesía vanguardista, surge una narrativa de similares orientaciones renovadoras, con autores como Joyce, Faulkner o Kafka.

En América Latina, en los años 20 y 30, es notorio el surgimiento de una poesía vanguardista (con figuras tan notables como Huidobro, Vallejo o Neruda), pero en esos años no se aprecia en la narrativa doras de filiación vanguardista de similar valía. Se mencionan por cierto algunas obras que constituyen casos relativamente aislados, no de una envergadura comparable a la de poemarios como Altazor, Trilce o Residencia en la tierra". Recién desde los años 40 se verán surgir doras narrativas mayores impactadas por el vanguardismo, y quienes más contribuyen en esa fase son escritores pertenecientes a la que cabe llamar "generación vanguardista", la de Huidobro, Vallejo y Neruda, escritores como Asturias, Borges y quien más nos interesa, Alejo Canpentier.

La etapa formativa de Carpentier como escritor lo sitúa de lleno en el periodo de las vanguardias históricas, entre fines de la Primera Guerra Mundial y comienzos de la década del treinta. Carpentier inicia su actividad literaria en el marco de un grupo de vanguardia cubano, el grupo minorista, y colabora con la importante Revista de avance. Como muchos vanguardistas, considera que el cambio artístico y el cambio social, la vanguardia literaria y la vanguardia política, deben estar estrechamente ligados. El joven Carpentier está, pues, muy vinculado con los grupos de la izquierda cubana y se enfrenta a la dictadura de Gerardo Machado, por lo que sufrirá prisión y luego tendrá que huir 
del país en 1928, utilizando en su fuga los documentos del poeta francés Robert Desnos 5 .

Como muchos vanguardistas latinoamericanos, vive intensamente la experiencia europea (en su caso, entre 1929 y 1939) . Allí frecuentó entre otros a nuestro César Vallejo y allí publicó su primera obra, la novela Ecue-Yamba-O. En París vive la efervescencia vanguardista y recibe en particular una fuerte influencia del surrealismo. Le impactó el rechazo surrealista a la razón utilitaria (lo que Habermas llamaría la razón instrumental) , y la búsqueda de altemativas en una suprarrealidad pre o extrarracional: el inconsciente, lo onírico o el recurso a la escritura automática. Hay que anotar, sin embargo, que carpentier jamás cultivó propiamente esta última técnica.

Por otra parte, el cuestionamiento vanguardista a la racionalidad occidental lo condujo también a un interés por las culturas denominadas "primitivas". En el caso de Canpentier, ello se tradujo en un marcado interés por la cultura africana, componente tan importante en la forja de la identidad cubana. Alejo Carpentier es un autor que tiene fama de narrador cosmopolita, de escritor hiperculto y mu europeizado. Sin embargo, su carrera literaria se inicia con un fuerte sesgo de interés por lo nacional abano, por lo local, lo regional ${ }^{6}$. Los inicios literarios de Carpentier están muy vinculados con el negrismo, con ese movimiento de revaloración del componente cultural afrocaribeño, cuya expresión más connotada es la poesía de Nicolás Guillén?.

La primera obra que publicó Carpentier fue la novela Ecue-Yamba-O (Alabado sea el señor, en lenguaje ñáñigo afrocubano), escrita en una primera versión en 1927 en las mazmorras del dictador Gerardo Machado y publicada en una versión más amplia en 1933. Esta novela, que relata la breve vida no tan feliz del campesino afrocubano Menegildo Cue, es una de las obras menos conocidas de Carpentier y, sin embargo, es, en muchos aspectos, una obra de gran interés y una de las pocas obras narrativas hispanoamericanas que evidencia tempranamente el impacto de las tendencias de vanguardia. En este texto buscó conjugar Carpentier dos opciones. De un lado, una escritura vanguardista, atenta a las últimas novedades internacionales, tachonada de metáforas audaces e imágenes rebuscadas. Del otro, un nativismo afrocubano que hace de Ecue-Yamba-O la novela más 
destacable del negrismo caribeño. Hay aquí un esfuerzo de revaloración del aporte africano a la cultura cubana, de reivindicación de una cultura oprimida y marginada, en un intento de replantear la problemática de la identidad nacional cubana integrando ese imprescindible componente. Destaca en especial un hondo interés por las creencias mágico-religiosas afrocubanas, por los rituales de la santería y el ñañigui:smo.

Esta preocupación por lo propio, por lo cubano y lo latinoamericano, a pesar de las apariencias de un refinamiento internacional, no dejará de estar presente a lo largo de toda la obra de Carpentier. Y en consonancia con ello, una preocupación ética por América Latina, por sus complejos problemas sociales, por sus raíces en el pasado, y una arraigada expectativa por las utopías de su futuro. Desde la juvenil conjunción de vanguardia artística y vanguardia social, Carpentier pasó por la asimilación de las teorías del compromiso sartreano, hasta llegar al apoyo a la revolución cubana, a la que sirvió desempeñando diversos cargos culturales y diplomáticos (al fallecer era embajador de Cuba en Francia). Tales inquietudes nunca dejaron de impactar de diversos modos en su producción literaria8.

Ia segunda novela de Carpentier, Eil reino de este mundo (1949), es en múltiples sentidos mu diversa de la primera. Sin embargo, hay una línea de contimuidad en cuanto al interés por el aporte africano a la cultura caribeña (en este caso centrado en el vaudou haitiano) . En cuanto a la escritura, vemos florecer en esta novela la prosa más típica de Carpentier, esa prosa barroca (o nedbarroca) , de gran refinamiento formal, atiborrada de alusiones cultistas, que será el signo distintivo de su producción narrativa en adelante. Como Borges, Carpentier es un escritor que construye sus textos en diálogo con otros textos, en una densa red intertextual. Otra innovación duradera se plasma en El reino de este munob, y es la orientación hacia el pasado, el interés por la historia, la búsqueda de los orígenes de la América Latina moderna, orígenes que explora en las postrimerías del siglo XVIII y los inicios del XIX, años que preparan y consolidan muestras independencias políticas. No es casual, pues, que esta primera novela histórica tenga como tema a la primera revolución emancipatoria de Latinoamérica, la de Haití. ${ }^{9}$ En esta novela y también en El siglo de las luces (1962), Carpentier explora la incidencia de la 
revolución francesa en nuestras revoluciones de la independencia. Así tenemos las figuras paradigmáticas de Henri Christophe, el Napoleón negro, emperador de Haití, o de Victor Hugues, el Robespierre del Caribe, quien arriba a las Anti llas portandb dos armas, la Declaración de los derechos del hambre y la guillotina.

Pero en El reino de este mundo, como ya se apuntó, persiste el interés por la cultura afrocaribeña y en particular por las creencias mágicoreligiosas. Esta novela inaugura una modalidad destinada a una larga fortuna en la narrativa de Hispanoamérica, la de lo real-maravilloso, con frutos tan notables como Cien años de soledad, de García Márquez, o tan recientes como las obras de Laura Esquivel o Isabel Allende. ${ }^{10}$ Carpentier se propone en esta novela inconporar una faceta de la realidad por entonces generalmente soslayada por otros escritores, la de las creencias mágicas y la cosmovisión mítica de los pueblos latinoamericanos. En la novela, por citar un solo episodio, asistimos a la gesta de un gran rebelde, Mackandal, dotado del poder de transformarse en diversos animales, y que a pesar de haber sido ejecutado por los colonialistas franceses, para el imaginario de los esclavos, no ha muerto y ha de retomar para liderar una nueva rebelión.

Como se apuntó, Carpentier recibió una fuerte influencia de los surrealistas franceses. Sin embargo, en el prólogo de El reino de este mundb reprocha a los surreal istas el empeñarse en fabricar artificiosamente lo maravilloso, y contrapone a este fatigoso afán la prol iferación de la maravilla en América Latina. El escritor de Nuestra América no tiene que inventar lo maravi lloso, pues se enfrenta cotidianamente con una realidad intrínsecamente alucinante, de manera que al pintar realistamente nuestro presente o nuestro pasado, no puede omitir esa faceta de la maravilla: creencias populares fabulosas, geografía exuberante, historia y personajes desmesurados.

Pero no toda la producción de Alejo canpentier puede adscribirse a esta vertiente de lo real-maravill loso. Lo que sí persiste es esa constante interrogación de los orígenes de América Latina, que explora ya sea desde el ángulo de la naturaleza primigenia (es el caso de la Amazonía venezolana en Los pasos perdidos) o desde el ángulo de la historia, sondeando a ese arquetipo recurrente de nuestra historia, el dictador, ${ }^{11}$ en El recurso del método (1974), o desmitificando y casi camavalizando 
a la figura fundacional de Cristóbal colón y al inverosímil, pero fidedigno intento de obtener su canonización, en su última novela El arpa y la sombra (1979). Imposible comentar siquiera brevemente en este corto artículo esas diversas obras, pero no quisiera concluir sin algunas reflexiones sobre una novela que juzgo la más lograda de Canpentier, El siglode las luces.

Esta es también una novela histórica ${ }^{12}$ y su marco es esa encrucijada, para Carpentier tan significativa, entre los siglos XVIII Y XIX. Aborda en concreto las repercusiones en el ámbito caribeño de las hondas conmociones sociales que por entonces agitaban a Europa, en particular la revolución francesa. Son evidentes, pues, las afinidades con Eil reino de este mundo. Las paradójicas consecuencias de la Revolución Francesa son el simultáneo arribo de las luces y el terror. (Ell sueño de la razón produce monstruos, como reza uno de esos grabados de Goya que Carpentier suele citar a modo de epígrafe en varios capítulos de esta novela) .

La actuación de los principales personajes de Ell siglo de las lucesplantea, entre ctras, la problenática del intelectual y suparticipaciónen la historia. Victor Hugues es el racionalista que actúa implacablemente, guiado por principios inamovibles, pero que se torna pragmático cuando esos principios colapsan: así pasa de abolir la esclavitud a restablecerla con igual eficiencia y decisión, al servicio de la razón de estado. Sofía es la intuitiva, arrastrada al compromiso histórico por un impulso espontáneo, como ocurre al final de la novela, cuando la urgencia de "hacer algo" la empuja a compartir el destino del pueblo madrileño sublevado contra Napoleón. Esteban es el vacilante, a veces ansioso de acción, movido por puros ideales, a veces desengañado, escéptico, marginándose en una actitud contemplativa. De algún modo, estas figuras expresan los dilemas de tantos intelectuales latinoamericanos, y en particular del propio Canpentier.

Alejo carpentier, el intelectual de perfil refinado y europeizante, nos ha legado a través de su obra una constante e incisiva reflexión sobre América Latina, su pasado y su destino, apostando por esa patria de la justicia ${ }^{13}$, por esa utopía que su compatriota José Martí denominaba Nuestra América. 
Cartos García-Bedoya M.

\section{Notas}

1 Carpentier nació el 26 de diciembre de 1904 y falleció el 24 de abril de 1980. El 2004 se conmemoraron, pues, los cien años de su nacimiento y en el 2005 un cuarto de siglo de su muerte.

2 Sobre el "boom", consúltese en especial el brillante trabajo de Ángel Rama (1982). También el libro de Emir Rodríguez Monegal, El Boom de la novela latinoamericana.

3 Este impacto del vanguardismo lo analiza mu acertadamente Gerald Martín.

4 Se suele mencionar la producción de figuras como Macedonio Fernández, Roberto Arlt, María Luisa Bombal o Pablo Palacio, entre otros. En el Perú el ejemplo más preclaro sería La casa de cartón, publicada en 1928 por un jovencísimo Martín Adán. La bibliografía sobre estos temas es más bien escasa; consúltese el libro de Pérez Firmat (1982) el volumen compilado por Fernando Burgos (1996) y la antología de Verani Narrativa vanguardista hispanoamericana.

5 Sobre aspectos biográficos brindan interesantes informaciones las Conversaciones con_Alejo Carpentier, compiladas por Ramón Chao (1988) .

6 Algo similar ocurre con el joven Borges criollista, fascinado por la mitología de los arrabales porteños. Esto lo ha analizado muy acertadamente Beatriz Sarlo (1988) , que nos devela a un Borges "otro".

7 Sus inicios lo ligan a la así llamada "vanguardia regionalista", opuesta a otra de orientación excluyentemente cosmopolita. Véase sobre esto los trabajos de Ángel Rama (1973) y de Nelson Osorio (1981) .

8 Sobre estos aspectos de su trayectoria intelectual, véase el libro de Roberto González Echevarría (1990), uno de los más relevantes consagrados a nuestro autor.

9 Esa nación proclamó su independencia en 1804. Coincidentemente, en el 2004 cumple Haití dos siglos de vida independiente. Cuba por su parte será la última de las naciones latinoamericanas en emanciparse, luego de la guerra iniciada por Martí en 1895 y terminada con la intervención norteamericana de 1898.

10 Sobre lo real-maravilloso o el realismo mágico, consúltese entre otros los libros de Víctor Bravo (1988) y de Seymour Menton (1993). Sobre el tema en la obra de Carpentier, véase el libro de Alexis Márquez Rodríguez (1982) y el ya citado texto de Roberto González Echevarría (1990) .

11 Sobre el tema del dictador en la novela hispanoamericana, consúltese los libros de carlos Pacheco (1987) y de Ángel Rama (1976) .

12 Sobre la novela histórica en Hispanoamérica, consúltese entre otros los libros de Seymour Menton (1993) y de Peter Elmore (1997) .

13 La expresión es de Pedro Henríquez Ureña.

\section{Referencias bibliográficas}

ARIAS, Salvador (compilador) (1977) : Recopilación de textos sobre Alejo Canpentier. Casa de las Américas. La Habana.

BRAV, JoséAntonio (1978) : Lo real maravi 7 loso en la narrativa latinoamericana actual: Cien años de soledad, Ell reino de este munb, Pedro Páramo. Editoriales Unidas. Lima. 
BRALO, Victor (1988) : Magias ymaravi7las en el continente literario: para un destinde del real ismo mágico y lo real maravi lloso. Eliciones La Casa de Bello. Caracas.

BURcos, Femando (editor) (1986) : Prosa hispánica de vanguardia. Orígenes. Madrid. CARPENIIHR, Alejo (1984) : "Lo barroco y lo real maravilloso" . En Ensayos, Letras Cubanas. Ia Habana; pp. 107-126.

đHAO, Ramón (1988) : Conversaciones con Alejo Cazpentier. Alianza Editorial, Madrid. EIMDRE, Peter (1997) : La fábrica de la memoria. La crisis de la representación en la novela histórica latinoamericana. Fondo de Cultura Económica. Lima.

GONZÁLEZ ECHEVARRÍA, Roberto (1990) : Alejo Carpentier. The pilgrim at home. University at Texas Press. Austin.

MÁRQQHZ RODRÍGUEZ, Alexis (1982) : Lo barroco y lo real maravill loso en la dbra de Alejo Canpentier. SigloXXI. NÉxico.

MARIIN, Gerald (1989) : Joumeys thraugh the Labyrinth. Verso. Iondres.

MENION, Seymour (1993) : La nueva novela histórica de la América Latina, 1979-1992. Fondo de Cultura Económica. México.

MENION, Seymour (1998) : Historia verdadera del realismo mágico. Fondo de Cultura Económica. México.

OSORIO, Nelson (1977) : "La nueva narrativa y los problemas de la crítica en hispanoamérica actual" Revista de Crítica Literaria Latinoamericana, 5 ; pp. 7-26.

OSORIO, Nelson (1981) : "Para una caracterización histórica del vanguardismo literario hispanoamericand" en Revista Iberoamericana 114-115; p.p. 227-254.

PACHCO, Carlos (1987) : Nanrativa de la dictadra y crítica literaria. Centro de Estudios Latinoamericanos Rómulo Gallegas. Caracas.

PEREZZ FIRVAT, Gustavo (1982) : Idle Fictions: The Hispanic Vanguard Novel, 19261934. Duke University Press. Durham.

RAMA, Ángel (1973) : "Las dos vanguardias latinoamericanas" en La riesgasa navegación del escritor exi7iadb. Arca. Mbntevideo, 1995; pp. 135-148.

RAMA, Ángel (1976) : Los dictadores latinoamericanos. Fondo de Cultura Económica. México.

RAMA, Ángel (1982) : La novela latinoamericana. Panoramas 1920-1980. Colaultura. Bogotá. 
Cartos García-Bedoya M.

RAMA, Ángel (1982) : "El Boomen perspectiva" . En La crítica de la aultura en América Latina. Biblioteca Ayacucho. Caracas 1985; pp. 266-306.

SARO, Beatriz (1988) : Borges, unescritor en las ori 7 las. Ariel. Buenos Aires.

VERANI, Hugo (selección e introđucción) (1996) : Narrativa vanguardista hispanoamericana. UNAM/Ediciones del Equilibrista. México. 